\title{
Human, snake, and environmental factors in human-snake conflict in North Bihar - a one-year descriptive study.
}

\author{
Takanungsang Longkumer ${ }^{\mathrm{a}}$, Lois Joy Armstrong ${ }^{\mathrm{b}}$, Vishal Santra ${ }^{\mathrm{c}}$, Philip Finny ${ }^{\mathrm{d}}$ \\ ${ }^{a}$ MBBS, PGDipFM, Duncan Hospital, Raxaul, Bihar, India (A Unit of Emmanuel Hospital Association) \\ ${ }^{\mathrm{b}}$ BSC, MPHTM, Duncan Hospital, Raxaul, Bihar, India \\ 'BA, MEnv Mgmt, Simultala Conservationists (Foundation for Wildlife), Nalikul, Hooghly, West Bengal, India \\ ${ }^{\mathrm{d}} \mathrm{MD}, \mathrm{DNB}(\mathrm{Med}), \mathrm{DNB}$ (Endo), Duncan Hospital, Raxaul, Bihar, India
}

\begin{abstract}
Background: The state of Bihar has the third largest number of snakebite deaths in India. The purpose of this study is to explore the factors related to human-snake conflicts in northwest Bihar and southern Nepal. Using these findings, various strategies were proposed to reduce the incidence of snakebites.

Method: Data were collected from 609 patients at Duncan Hospital in Raxaul, Bihar, India between 1 July 2012 and 30 June 2013. Patients were included if they had a history of snakebite or unknown bites. Patients with symptoms of envenomation but no known bites were also included, as were patients who were dead on arrival due to a snakebite.
\end{abstract}

Results: The 10-19 year old age group is the peak age group (28.4\%) for snakebite. There is a slight preponderance of males (52.7\%). $51.4 \%$ of bites occurred on the foot/ankle. The envenomation rate was $12.6 \%$. The mortality rate of those envenomed that arrived at the hospital alive was $6.3 \%$. Fourteen people were dead on arrival at the hospital.

$75 \%$ of people were unable to identify what, or what type of snake, bit them. Common Wolf Snakes (Lycodon aulicus) were the most common snakes brought to the hospital, followed by Spectacled Cobra (Naja naja). Patients who brought snakes to the hospital and attempted identification were all successful at identifying cobras, but all those who brought in Common Wolf Snakes incorrectly identified them as Kraits.

The highest monthly frequency of snakebites occurred between June and September; while on a daily basis, the highest frequency occurred between $1700 \mathrm{hrs}-2200 \mathrm{hrs}$, the time in which $39.1 \%$ of all bites occurred.

$59.2 \%$ of the bites occurred in and around the house. Farming, housework, sleeping, playing, and toileting in fields were the activities most commonly occurring when bitten. Sleeping on the floor increased the risk of envenomation $[\mathrm{OR}=5.8,95 \% \mathrm{Cl} 1.8-18.6]$, while sleeping under a mosquito net decreased the risk of envenomation [OR= $0.17,95 \% \mathrm{Cl} 0.04-0.6]$.

May 2016. Christian Journal for Global Health, 3(1): 36-45. 
Conclusion: Snakebite is a rural hazard in Northern Bihar, not just an occupational hazard. Use of toilets and sleeping on beds with well tucked in mosquito nets may help prevent snakebites. Education to reduce the risk of snakebites should begin in childhood and be regularly reinforced prior to the rainy season. Prevention measures should include environmental management such as keeping eating areas clean and keeping food storage and sleeping areas a distance apart.

\section{Introduction}

Human-snake conflict has been present for centuries, but in India, there is still much to learn about this neglected problem. The country has over 300 identified species in its various environments, out of which more than 60 are venomous. ${ }^{1}$ Humans are mostly envenomed by four of these species that encroach upon human habitats and agricultural fields as well as the areas around them, namely: Spectacled Cobra (Naja naja), Common Krait (Bungarus caeruleus), Russell's Viper (Daboia russellii), and Saw Scaled Viper (Echis carinatus). ${ }^{1}$

Many snakebite deaths occur in settings where there is poor recording of causes of deaths, and so the best available estimates are used. In 1998, Chippaux estimated that worldwide, there are 125,000 deaths per year and 10,000 of those from Asia. ${ }^{2}$ India, we know, makes up a large part of this figure. The best Indian estimate is currently 45,900 deaths per year due to snakebite from the work of the Million Death Study. ${ }^{3}$ They suggest, that in keeping with this data, the number of deaths worldwide is well over 100,000 per year. ${ }^{3}$ Snake venom acts in a variety of ways including: paralysis caused by neurotoxicity, bleeding disorders, local tissue damage, renal tissue damage, and rhabdomyolysis. Some may have just one action and others may have a combination of the above list; some may even show regional variation within a species. Currently in India, there is only anti-venom for the four main species: Spectacled Cobra, Common Krait, Russel's Viper, and Saw-Scaled Viper.

Each year in Bihar, 4500 deaths are attributed to snakebites. This makes it the state with the third highest number of snakebite deaths in India after Uttar Pradesh and Andhra Pradesh. ${ }^{3}$ Bihar is one of India's poorest and least resourced states in terms of its health services. ${ }^{4,5}$ Duncan Hospital in the East Champaran District of Bihar admits approximately 500 patients annually from both northern Bihar and the plains of southern Nepal who have been bitten by snakes. While data on epidemiology, outcomes, and determinants of snakebites are available from Nepal, ${ }^{6-8}$ the same information is lacking from Bihar. Envenomation is a deadly consequence of snakebites, especially in regions like East Champaran, where victims often travel for many hours to reach a health facility.

Unpublished data from a retrospective chart review showed that 367 people presented to Duncan Hospital, Raxaul, in 2011 with snakebites, bites of unknown origin (but suspected of being a snakebite), and signs of envenomation with no known bite. Most patients in this data set were between 11-15 years old and $13.3 \%$ presented with neurotoxic envenomation. No syndromes of coagulopathy were seen. $51 \%$ of the patients with neurotoxic symptoms also had tissue damage or inflammation at the local bite site, which are findings consistent with the effects of a cobra bite. The venomous snakes were assumed to be cobras and kraits, as these are the venomous snakes common to this region.

The overall envenomation rate at Duncan Hospital (13.3\%) was lower in the 2011 data set in comparison to the $52 \%$ envenomation rate of Sharma et al. ${ }^{7}$ Probable reasons for this are that our region is inhabited by a large number of nonvenomous snakes or that many people die prior to reaching health facilities.

This study was designed to look at which human, snake, and environmental factors influence the likelihood of being bitten by a snake 
in the East Champaran region of North-west Bihar and Southern Nepal. This information is aimed at providing public education on how to prevent snakebites and, therefore, decrease the mortality and morbidity due to snakebites. Data on the factors relating to mortality of snakebites will be published elsewhere.

\section{Materials and Methods}

Information on human, snake, and environmental factors related to snakebites were collected from 615 people who presented between 1 July 2012 and 30 June, 2013. Patients were included if they had been bitten either by a snake, or an unknown source, or presented with symptoms of snake envenomation without a known snakebite. In the retrospective chart review, bites from unknown sources had shown an envenomation rate of $8.2 \%$. This is only $40 \%$ lower than the $13.3 \%$ of envenomation rate in known snakebites. Bites from unknown sources were therefore included in the present study. Patients who were dead on arrival who had been bitten by a snake were included in the study. The study was explained to patients and/or their attending relatives in a relevant language, and verbal consent was obtained to collect the data.

Patients were included in the study if they presented to the hospital within 24 hours of the time of the bite or had symptoms of envenomation. The following observations were recorded: location of bite, time of bite, time taken to reach the hospital, location of victim at time of bite, and victim activity at time of bite. Patients were asked to attempt identifying the snake if seen. Dead snakes brought to the hospital were photographed and preserved in formalin. At the end of the study, the preserved snakes were identified to the species level by a person skilled in the classification of snakes. Information was also obtained related to delays encountered during travel to the hospital, first aid or treatment prior to arrival at the hospital, and treatment given at the hospital. Data was collected on pre-printed case report forms and, subsequently, converted into an electronic format. Epi Data 3.1 was used to generate descriptive statistics. VassarStats (www.vassarstats.net) was used to analyse further data.

Permission to conduct this study was obtained from the Emmanuel Hospital Association Research and Ethics Committee (Proposal number 77).

\section{Results}

Out of the 615 patients from whom data was collected, six cases were excluded for the following reasons: scorpion bite (1), spider bite (1), did not meet inclusion criteria for time of presentation to the hospital (1), snake's blood splashed into eyes while killing a snake (1), not bitten by a snake or any other animal (2). Some of these patients were initially included as their anxiety made it difficult to get an accurate history. $352(58 \%)$ of the patients came from India and $256(42 \%)$ from Nepal. One person did not have an address recorded.

\section{Human Factors}

Table 1 shows that males made up $52.7 \%$ of the population $(n=321)$, and $47.3 \%$ of the population was female $(n=288) .28 .4 \%$ of the population was between 10 and 19 years of age. Only in the 30-39 year old age range did we find more women bitten than men.

\begin{tabular}{|c|c|c|c|}
\hline Age (yrs) & Total & Male & Female \\
\hline $0-9$ & 54 & 35 & 19 \\
\hline $10-19$ & 173 & 93 & 80 \\
\hline $20-29$ & 125 & 63 & 62 \\
\hline 30-39 & 123 & 53 & 70 \\
\hline $40-49$ & 69 & 35 & 34 \\
\hline $50+$ & 65 & 42 & 23 \\
\hline Total & 609 & 321 & 288 \\
\hline
\end{tabular}

The distal limbs (foot and hand) were the most common bite sites $(\mathrm{n}=457,75.8 \%)$, and $51.4 \%$ of the bites were on the foot and ankle. Significantly, more bites were present on the right side of the body $(n=304)$ compared to the left $(\mathrm{n}=286, \mathrm{p}=0.033)$.

Fang marks were present in $42 \%$ of the 
patients ( $\mathrm{n}=256)$, but evidence of fang marks was obscured by incisions or burn marks in $7 \%$ ( $\mathrm{n}=$ 43) and absent in 34.3\% $(n=209)$ cases. $19.4 \%$ of the patients with fang marks were envenomed, and $3.8 \%(n=6)$ of patients without fang marks were envenomed.

A total of 77 people (12.6\%) were envenomed, including all 14 patients who were dead on arrival at the hospital. Out of the envenomed patients who arrived at the hospital alive, four died in the hospital (mortality rate $=6.3 \%$ ). Two patients were referred to outside centres; two were discharged at the request of relatives and were expected to die as they had not regained any signs of consciousness during the 72 hours post resuscitation.

\section{Activity at time of snakebite}

Complete data on victims' activity at the time of the snakebite is recorded in Table 2.

Table 2. Activity at time of snakebite

\begin{tabular}{lll}
\hline Activity & Number & Percent \\
\hline Farming & 139 & 22.8 \\
Walking/running & 115 & 18.9 \\
Housework & 77 & 12.6 \\
Sleeping & 69 & 11.3 \\
Playing & 55 & 9.0 \\
Toileting in field & 50 & 8.2 \\
Sitting/standing - stationary & 26 & 4.2 \\
Collecting water/fishing & 9 & 1.4 \\
Moving bricks/sticks/objects & 9 & 1.4 \\
Opening/closing gates or doors & 5 & 0.8 \\
Leaning on wall/fence/roof & 4 & 0.6 \\
Doing Pooja/worship & 4 & 0.6 \\
Missing & 32 & 5.2 \\
Other* & 15 & 2.4 \\
Total & 609 & \\
\hline
\end{tabular}

Note. $*$ This includes house building, demolition, maintenance -2 , getting off a bed -2 , geting or putting on shoes -2 , killing or removing snake -2 , putting hand in or closing rat hole -2 , road making, brushing teeth, catching a mouse, working (vague), bike riding - all 1 each.

Additional information was collected from the 69 victims who were sleeping at the time they were bitten. 19 people were sleeping on the floor and 47 on a bed (data missing $=3$ ). Twenty six individuals used a mosquito net and 40 did not use a mosquito net (data missing $=3$ ).

\section{Location of victim at time of bite}

$59.2 \%$ of the bites occur in and around the house. $29.3 \%$ of bites occurred in fields and jungles. Complete information on locations where victims were bitten are recorded in Table 3 .

Table 3. Location of victim at time of snakebite

\begin{tabular}{lll}
\hline Location & Number & Percentage \\
\hline Outside but in the vicinity of the house & 194 & 31.8 \\
Fields and jungles & 179 & 29.3 \\
Inside house & 167 & 27.4 \\
Road and pavements & 35 & 5.7 \\
Waterbodies & 22 & 3.6 \\
Others (school, factory, railway, temple) & 4 & 0.65 \\
Not recorded & 8 & 1.3 \\
Total & 609 & 100 \\
\hline
\end{tabular}

\section{Snake Factors}

214 people (35\%) did not see what bit them, but they came to hospital because they thought it was most likely a snake. $234(40 \%)$ had seen a snake bite them, but could not identify the type of snake. $152(25 \%)$ people made an attempt to 
identify the type of snake. Of the identified snakes, 86 claimed to have been bitten by a Krait, 46 by a Cobra, 14 by a Water Snake (Local name Pani Saap), 3 by a Rat Snake (Local name Dhaman), 2 by a Wolf Snake, and 1 by a King Cobra. The following were identified from the collection of preserved snakes: Common Wolf Snake (Lycodon aulicus) (21), Spectacled Cobra (Naja naja) (11), Common Kukri Snake (Oligodon arnensis) (1). There were no Common Kraits (Bungarus caeruleus) collected during this study, but some have been brought to the hospital by patients since the study was completed. No Russell's Vipers were brought in by patients during this study, and to date, they still have not been recorded in the area. Of the 11 cobras brought in for identification, seven of these caused envenomation (63.6\%).

Twenty people who brought in snakes had attempted identification of these snakes. Ten out of ten victims correctly identified cobras; however, ten out of ten victims identified Wolf Snakes as Common Kraits. Out of those who identified the snake as venomous, $19.5 \%$ were envenomed, while $7.7 \%$ of patients were envenomed though the snakes were identified by victims or their families as non-venomous. Out of those who presented with bites of unknown predators, $14 \%$ were envenomed.

\section{Environmental Factors}

$79.1 \%$ of snakebites occurred during Bihar's rainy season that runs from June to September. Only 4 snakebites $(0.6 \%)$ occurred within the coldest winter months of December and January. $39.1 \%$ of all snakebites occurred between $1700 \mathrm{hrs}$ and $2200 \mathrm{hrs}$, with the highest frequency between 1900h and $2000 \mathrm{hrs}$ (Figure 1).

Figure 1. Snake envenomation according to time of day

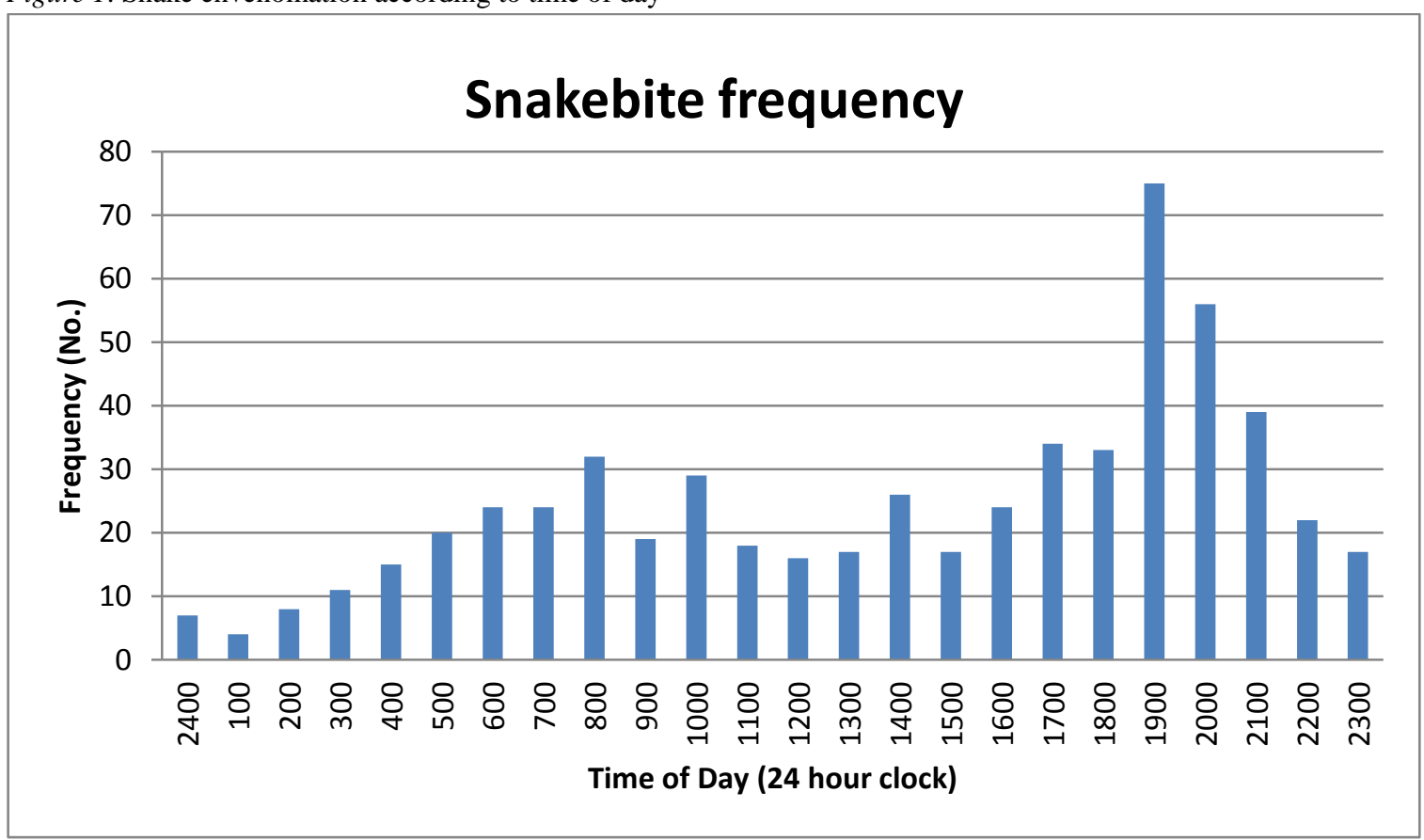

There were 55 people who had complete data for the time of bite and the syndrome of envenomation. Twenty eight envenomations occurred in the daylight hours (0600 to $1800 \mathrm{hrs})$, and 27 envenomations occurred at night (18000600hrs). Dusk and dawn only vary around 30 minutes either side of this during the year. During the period $1800-0600$ hrs, $44.4 \%$ of the envenomations had solely neurotoxic symptoms in comparison to $21.4 \%$ between $0600-1800 \mathrm{hrs}$. Neurotoxic syndromes associated with tissue damage were higher between 0600-1800hrs (78.6\%) compared to between $6 \mathrm{pm}$ and $6 \mathrm{am}$ $(55 \%)$. When tested for difference in proportions, 
they were found not to be significant $(\mathrm{p}=0.0689$, two tailed test).

\section{Envenomation Syndrome}

All of the 77 envenomed patients had neurotoxic envenomation syndrome. Tissue damage was recorded in 38 cases, while 29 had no tissue damage present. In nine patients, there was no documentation regarding the presence or absence of tissue damage. One patient from Nepal presented with bleeding from the mouth and nose. The patient had been administered four vials of Anti Snake Venom (ASV) at a peripheral hospital, and on arrival at Duncan Hospital, his clotting parameters were within the normal range. He was the first patient with a syndrome of clotting abnormality seen at the hospital in 7 years. The snake was not seen by the patient. The bite occurred in the Himalayan foothills of Nepal.

\section{Risks of envenomation}

The odds ratio for being envenomed while sleeping on floor in comparison to someone who slept on a bed was 5.8 [95\% CI $=1.8-18.6]$. The odds ratio for being envenomed while sleeping under a mosquito net in comparison to someone who did not sleep under a mosquito net was 0.17 [95\% CI $=0.04-0.6]$.

\section{Recommendations and Discussion}

Two tables of recommendations with their rationale are given below. The first lists recommendations for health care workers (Table 4), and the second gives recommendations for community education (Table 5). As their rationale is given in the table, it will otherwise not be discussed in this discussion unless extra explanation is required.

Table 4-Recommendations for health care workers

\begin{tabular}{|c|c|c|}
\hline & Recommendation for health care workers & Rationale \\
\hline 1 & $\begin{array}{l}\text { Use the months of April and May to: } \\
\text { - } \quad \text { Procure the necessary stocks of ASV } \\
\text { - Train health care workers in snakebite } \\
\text { management } \\
\text { - Educate the community on snakebite } \\
\text { prevention and first aid. }\end{array}$ & $\begin{array}{l}80 \% \text { of bites occur during the months of June- September so } \\
\text { preparedness and prevention need particular attention in the time } \\
\text { leading up to this "epidemic" season. }\end{array}$ \\
\hline 2 & $\begin{array}{l}\text { Envenomation should not be excluded by the } \\
\text { absence of fang marks. }\end{array}$ & $\begin{array}{l}3.8 \% \text { of people without fang marks were envenomed. Krait bites, } \\
\text { in particular, can be hard to visualise, even a short time after the } \\
\text { bite. }\end{array}$ \\
\hline 3 & $\begin{array}{l}\text { Consider snakebite in the differential diagnosis of } \\
\text { unexplained altered sensorium, alteration to speech } \\
\text { and swallowing, and abdominal pain, especially } \\
\text { during the rainy season. }\end{array}$ & $\begin{array}{l}\text { Patients can present with symptoms of envenomation, without any } \\
\text { history of being bitten by a snake. }\end{array}$ \\
\hline 4 & $\begin{array}{l}\text { Bites by an unknown predator need to be taken } \\
\text { seriously and observed for signs of envenomation. }\end{array}$ & $\begin{array}{l}14 \% \text { of people, who were unable to identify what predator bit } \\
\text { them, were envenomed. }\end{array}$ \\
\hline 5 & $\begin{array}{l}\text { Don't rely on the ability of patients or relatives to } \\
\text { identify snakes. }\end{array}$ & $\begin{array}{l}\text { Identification of snake species is poor, although it is better for } \\
\text { cobras. }\end{array}$ \\
\hline 6 & $\begin{array}{l}\text { Antivenom should only be given to patients } \\
\text { showing symptoms of envenomation. }\end{array}$ & $\begin{array}{l}\text { Envenomation of patients only occurred in } 63.6 \% \text { of the cases } \\
\text { where cobras were brought. To give anti venom without } \\
\text { symptoms of envenomation exposes people to the risk of adverse } \\
\text { reactions and is costly, especially in a setting where demand } \\
\text { exceeds supplies. }\end{array}$ \\
\hline 7 & $\begin{array}{l}\text { Consider the production of a bivalent ASVfor } \\
\text { regions of north India and Nepal. }\end{array}$ & $\begin{array}{l}\text { Saw scaled and Russell's vipers are not present in this region and } \\
\text { a bivalent anti venom is likely to cause less adverse reactions. }\end{array}$ \\
\hline
\end{tabular}

May 2016. Christian Journal for Global Health, 3(1): 36-45. 
Table 5-Recommendations for Community Education

\begin{tabular}{|c|c|c|}
\hline & $\begin{array}{l}\text { Recommendations for community } \\
\text { education }\end{array}$ & Rationale \\
\hline 1 & $\begin{array}{l}\text { A large part of the public health education } \\
\text { needs to be directed to children and young } \\
\text { people, to both genders. }\end{array}$ & $\begin{array}{l}\text { The } 10-19 \text { year old age group is the peak age interval for bites. Numbers } \\
\text { of males and females bitten are almost equal. }\end{array}$ \\
\hline 2 & $\begin{array}{l}\text { Encourage the use of footwear and long } \\
\text { pants/trousers. }\end{array}$ & $67 \%$ of bites occur on the feet and legs. \\
\hline 3 & $\begin{array}{l}\text { The use of a stick to scare away snakes, prior } \\
\text { to working in an area with one's hands. }\end{array}$ & $\begin{array}{l}\text { This would decrease the number of bites where hands are put into snake } \\
\text { micro habitats without prior visualisation of the area. }\end{array}$ \\
\hline 4 & $\begin{array}{l}\text { Improved lighting using: } \\
\text { - } \quad \text { Torches when walking outside } \\
\text { - } \quad \text { Lighting in and around houses. }\end{array}$ & $\begin{array}{l}40 \% \text { of bites occur between } 1700-2200 \text { hours. } 59.2 \% \text { of bites occur in } \\
\text { and around the house. Lighting will enable better visualisation of } \\
\text { snakes. }\end{array}$ \\
\hline 5 & $\begin{array}{l}\text { Provision of toilets and education regarding } \\
\text { their use. }\end{array}$ & $\begin{array}{l}8 \% \text { of bites occurred when people were going to the fields for the } \\
\text { purpose of open defecation. }\end{array}$ \\
\hline 6 & $\begin{array}{l}\text { Encourage people to sleep on a bed and } \\
\text { under a well tucked-in mosquito net. }\end{array}$ & $\begin{array}{l}10 \% \text { of people were bitten while they were sleeping. Sleeping on the } \\
\text { ground, increases your risk of envenomation, sixfold. Sleeping under a } \\
\text { mosquito net, decreases your risk of envenomation, six fold. }\end{array}$ \\
\hline 7 & $\begin{array}{l}\text { Provision of buffer zones between fields and } \\
\text { housing areas. }\end{array}$ & $\begin{array}{l}59.2 \% \text { of bites occur in and around the house. Snakes are attracted to the } \\
\text { rodents who come for grain being grown. Keeping these distances } \\
\text { separate may help in decreasing the encroachment of snakes in housing } \\
\text { areas. }\end{array}$ \\
\hline 8 & $\begin{array}{l}\text { Make sleeping areas separate from food } \\
\text { storage, preparation and consumption areas. }\end{array}$ & $\begin{array}{l}\text { The presence of rodents in food related areas is prone to attract snakes. } \\
\text { If people sleep in places away from areas of the house connected with } \\
\text { food, this may decrease the risk of people connecting with snakes. }\end{array}$ \\
\hline
\end{tabular}

In contrast with previous studies, a majority (59\%) of the snakebites in the present study were located in and around houses. ${ }^{7,9-12}$ In this study, only $29 \%$ of victims were bitten in fields and jungles, which suggests snakebites to be primarily a rural hazard affecting both males and females, not just an occupational hazard affecting males.

The high frequency of bites on lower limbs is to be expected as the ground is the normal habitat of most snakes. The use of footwear covering the whole foot and long pants covering the lower limbs would be expected to reduce the incidence of snakebites, but as the majority of people live below the poverty line in rural India, this would be an expensive change of practice.

Although the presence of fang marks made it much more likely that a person had been envenomed, their absence did not mean that envenomation could be excluded as $3.8 \%$ of patients who did not present with fang marks were envenomed. The inability to see bite marks is most likely with the Common Krait (Bungarus caeruleus) bites, as juvenile or sub-adult kraits have extremely small, fine fangs that do not leave a visible mark that lasts for long after the bite has occurred. Additionally, krait venom does not cause tissue damage and this also makes the bite site less visible.

Seventy-five percent of people were unable to identify or provide the hospital with any information identifying the snake by which they were bitten. If specific anti-venoms were available, health care professionals would be unable to rely on patients for information about which species bit them. However, if the absence of the two main vipers in this region can be mapped more carefully, there may be a case to consider making a bivalent venom to cover the neurotoxic bites of the Spectacled Cobra and the Common Krait. This could be relevant for this heavily populated region of northern Indian and the plains of Nepal. ${ }^{6-8}$

Of the people who did not know what bit them, $14 \%$ showed signs of envenomation. This can be attributed to the high frequency of bites that occur after dark (around 1800hrs) and the lack of electricity in rural areas that renders victims unable to see what bit them. This is slightly higher than the overall envenomation rate of $12.6 \%$ and indicates that bites by unknown 
predators need to be taken seriously.

Victims were able to identify cobras more than any other snake while non-venomous Common Wolf Snakes were commonly mistaken for Kraits (Figure 2 and 3). Common Wolf snakes have a number of similar features to Common Kraits, and another aim of public education should be teaching the community how to distinguish between the two species in order to prevent the killing of the non-venomous Common Wolf snake. A poster of the common snakes of this region could be helpful to educate the community regarding snake identification.

\section{Figure 2: Common Krait}

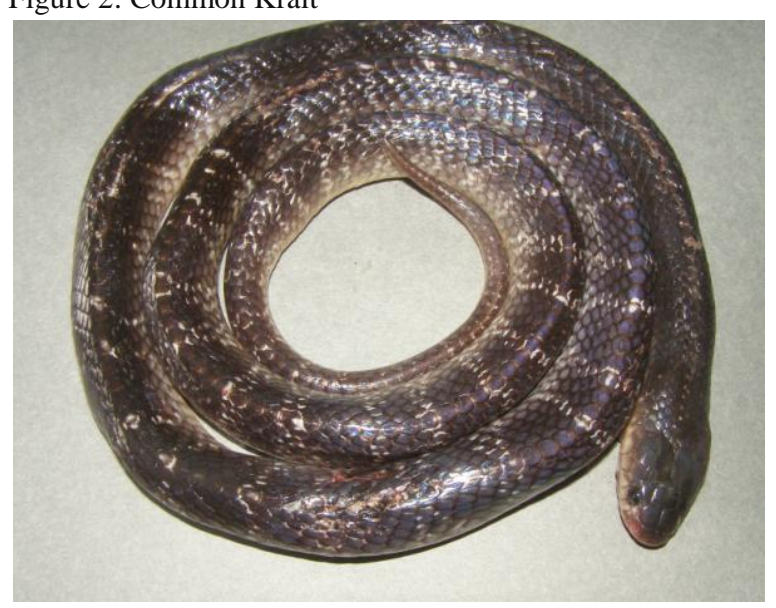

Figure 3: Common Wolf Snake

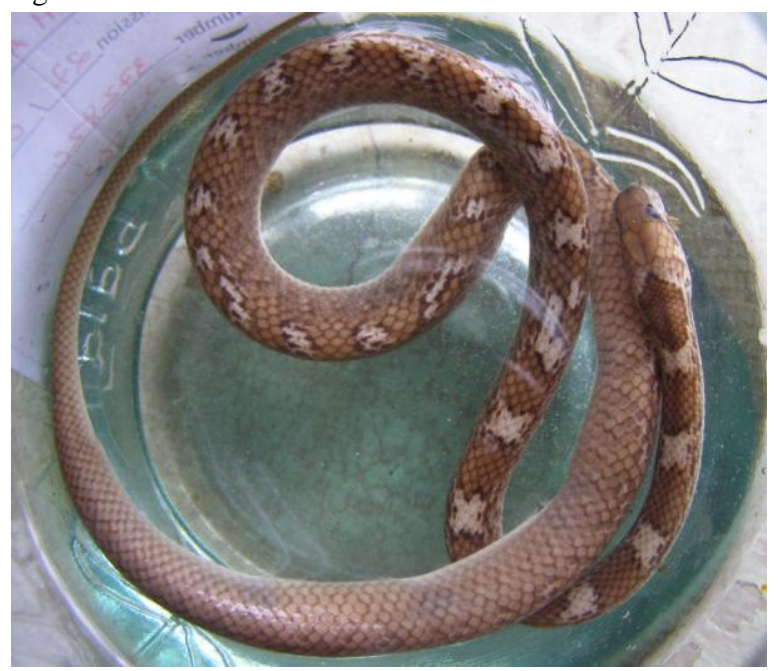

The highest frequency of snakebites occurred between $1900 \mathrm{hrs}$ to $2000 \mathrm{hrs}$ (just after dusk) and $40 \%$ of all snakebites occurred between $1700 \mathrm{hrs}$ to $2200 \mathrm{hrs}$, showing it to be a time of significant human/snake conflict. Crepuscular snakes, most active at dusk and dawn, are most likely to be hunting at this time. In addition, human activity also increases in the cool of the evening. In the evening, the use of a strong torch when going out and adequate lighting at home can help make snakes more visible and prevent people from inadvertently stepping on snakes.

Neurotoxic bites, "without tissue damage," occur more frequently at night, and this frequency matches the habits of the Common Krait that usually hunts between midnight and 6 a.m. Conversely, the neurotoxic bites with tissue damage, consistent with cobra bites, are more likely to occur in the daytime.

The high incidence of bites in and around the house may also be attributed to overcrowded houses, which often do not have clear demarcations between the kitchen, food store room, and bedroom. Without these clear boundaries, food and grain storage facilities, which entice rodents, can be in close proximity to sleeping areas. In order to prevent snakes, the natural predator of rodents, from entering the home, it is important to keep food as inaccessible to rodents as possible. Additionally, environmental management, including the construction of buffer zones between the fields/jungle and housing areas, can decrease the likelihood of snakes encroaching on residential areas.

In East Champaran, only $19.4 \%$ of people have a toilet facility. This means over $80 \%$ of the population use open fields for toileting. ${ }^{13}$ In this study, $8 \%$ of people were bitten when they went out to the fields for sanitation purposes, including three who were envenomed. Provision of toilet facilities close to houses and educating people to use them will assist in lowering the incidence of snakebites.

The National Snakebite Management Protocol provides the countrywide basis for care of patients with snakebite. ${ }^{14}$ The regional document is the WHO SEARO Guidelines. ${ }^{15}$ Both documents have sections on snakebite prevention, although most of the documents deal with snakebite management. None of the recommendations given in this study disagree with the National Protocol or the WHO SEARO Guide- 
lines, but they do provide some extra information that could decrease the incidence of snakebites in this region. The recommendation of a bivalent anti-venom is a regional recommendation that is not relevant to the whole country. However, it is important, as the country is increasingly recognising there are regional issues regarding snakebites and their management.

There are continuing needs for improvements in snakebite first aid and management; in addition, it would seem only prudent that further work needs to be done to prevent snakebites. First, there needs to be community based studies to provide accurate incidence rates of snakebites and their mortality and morbidity. Second, there needs to be community intervention projects, using locally relevant recommendations. Finally, there needs to be re-evaluation of community interventions to show which are the most useful in decreasing the incidence of snakebites and their associated mortality.

\section{References}

1. Whitaker R, Captain A. Snakes of India - The Field Guide. $1^{\text {st }}$ ed. Chennai: Draco Books; 2008.

2. Chippaux J-P. Snake-bites: an appraisal of the global situation. Bull WHO 1998; 76:515-24.

3. Mohapatra B, Warrell DA, Suraweena W, Bhatia P, Dhingra N, JOTKAR RM, et al. Snakebite mortality in India: a nationally representative mortality survey. PLoS Negl Trop Dis. 2011;e1018. http://dx.doi.org/10.1371/journal.pntd.0001018

4. Department of Health, Government of Bihar. Monitorable goals of the $11^{\text {th }}$ Plan. 2009. http://planning.bih.nic.in/Ppts/PR-05-02-12-2009.pdf

5. State Health Society Bihar. Manpower management. 2008

http://www.statehealthsocietybihar.org/manpower$\underline{\text { mgmt.html }}$

6. Sharma SK, Khanal B, Pokhrel P, Khan A, Koirala S. Snakebite re-appraisal of the situation in Eastern Nepal. Toxicon. 2003;41:285-9.
7. Sharma S, Chappuis F, Jha N, Bovier PA, Loutan L, Koirala S. Impact of snake bites and determinants of fatal outcomes in Southeastern Nepal. Am J Trop Med Hyg. 2004;71(2):234-8.

8. Pandey DP. Epidemiology of snakebites based on field survey in Chitwan and Nawalparasi Districts, Nepal. J Med Toxicol. 2007;3(4):164-8.

9. Kirte RC, Wahab SN, Bhathkule PR. Record based study of snake bite cases admitted at Shri Vasantrao Naik Government Medical College and Hospital, Yavatmal (Maharashtra). Indian J Public Health. 2006;50: 35- 7.

10. Majunder D, Sinha A, Battacharya SK, Ram R, Dasgupta U, Ram A. Epidemiological profile of snake bite in 24 Parganas District of West Bengal with focus on underreporting of snake bite deaths. Indian J Public Health. 2014;58(1):17- 21. http://dx.doi.org/10.4103/0019-557X.128158

11. David S, Matathia S, Christopher S. Mortality predictors of snake bite envenomation in Southern India - A ten-year retrospective audit of 533 patients. J Med Toxicol 2012;8:118-23. http://dx.doi.org/10.1007/s13181-011-0204-0

12. Kalantri S, Singh A, Joshi R, Malamba S, Ho C, Ezoua $\mathrm{J}$ et al. Clinical predictors of in-hospital mortality in patients with snakebite: a retrospective study from a rural hospital in central India. Trop Med Int Health. 2006;11(1): 22-30. http://dx.doi.org/10.1111/j.1365-3156.2005.01535.x

13. Annual Health Survey 2010-11, Bihar. [Internet].[Cited 2014 June 30]. Office of the Registrar General and Census Commissioner, India; 2012. www.jsk.gov.in/ahs10/bihar.pdf

14. National snakebite management protocol. Directorate General of Health Services. Ministry of Health and Welfare, Government of India. 2009.

15. Warrell, DA. Guidelines for the clinical management of snake bites in the South-East Asia Region. SEARO Office of WHO: New Delhi. 2010. http://apps.searo.who.int/PDS_DOCS/B4508.pdf 
Peer Reviewed

Competing Interests: None declared.

Correspondence: Takanungsang Longkumer, Duncan Hospital, India. taka.longkumer@gmail.com Lois Joy Armstrong, Duncan Hospital, India. loisjarmstrong@gmail.com Vishal Santra, Simultala Conservationists, Nalikul, Hooghly, West Bengal, India. vishal.herp9@gmail.com Philip Finny, Duncan Hospital, India. philip.finny@gmail.com

Cite this article as: Longkumer T, Armstrong LJ, Santra V, Finny P. Human, snake, and environmental factors in human-snake conflict in North Bihar - A descriptive study. Christian Journal for Global Health (May 2016), 3(1):36-45.

(C) Longkumer T, Armstrong LJ, Santra V, Finny P This is an open-access article distributed under the terms of the Creative Commons Attribution License, which permits unrestricted use, distribution, and reproduction in any medium, provided the original author and source are properly cited. To view a copy of the license, visit http://creativecommons.org/licenses/by/3.0/

wWw.cjgh.org

May 2016. Christian Journal for Global Health, 3(1): 36-45. 